\title{
Estudios recientes sobre métodos de ensayo de resistencia al hielo (*)
}

\author{
L'Industria Italiana dei Laterizi, noviembre-diciembre 1971, n 6, pág. 219
}

En estos últimos años se han llevado a cabo numerosas investigaciones, en el campo de la resistencia al hielo, de los productos cerámicos y, en particular, de las tejas. Tales estudios pueden dividirse en dos clases: por una parte, aquellos que tratan de poner a punto métodos de ensayo que corresponden lo más posible con las condiciones que se presentan en la naturaleza, y por otra, aquellos que investigan las relaciones que puedan existir entre la heladicidad y las características físicas del cuerpo cerámico, principalmente mediante el examen al microscopio y la determinación del reparto del tamaño de los poros.

Para la valoración de la resistencia al hielo, partiendo de las características de la materia prima, se debe tener en cuenta principalmente el análisis granulométrico, en lo que se refiere a un control regular del reparto de tamaños de las partículas aisladas, lo cual ha revelado ser indispensable para tal fin. Como medio auxiliar se puede recurrir a la determinación de la superficie específica, que también proporciona indicaciones sobre la naturaleza de los materiales arcillosos presentes (caolinita, illita, montmorillonita).

Una investigación llevada a cabo sobre once arcillas holandesas adecuadas para la producción de tejas ha dado, por ejemplo, los siguientes resultados:

- partículas superiores a las $20 \mu: 35,3 \%$ de media, $29,0 \%$ de mínima y 42,3 \% de máxima ;

- partículas entre 2 y $20 \mu: 26,8 \%$ de media, $22,1 \%$ de mínima y $32,4 \%$ de máxima, y

- partículas inferiores a $2 \mu: 37,9 \%$ de media, $31,2 \%$ de mínima y $42,1 \%$ de máxima.

En lo que se refiere a la influencia del procedimiento de moldeo, se expone la diversidad de opiniones sobre la técnica del vacío. En el caso de Holanda, ésta se viene practicando generalmente con éxito y el vacío debe ser lo más constante y elevado posible.

De acuerdo con investigaciones llevadas a cabo por Pels Leusden, puede haber influencia, además, sobre la heladicidad por pequeñas variaciones en la forma de la galleta y de los moldes.

Respecto a la influencia de la cocción, se han realizado varias investigaciones por Enberg, Amrein y Gloor, Piltz, Assenmacher, así como por Rijken y Schouten.

(*) Resumen de un artículo de A. I. Rijken, publicado en la revista holandesa "Klei", en el cual se exponen en síntesis los resultados de 19 estudios desarrollados en estos últimos años en diversas naciones. 
Para la determinación del tamaño de los poros en el material cocido, se viene utilizando en diversos laboratorios el porosímetro de mercurio. Como complemento de este método se efectúa un examen al microscopio de secciones muy delgadas, examen que da una idea de la porosidad y de la magnitud de los poros aislados. Los dos métodos pueden emplearse al mismo tiempo.

En una colección de cinco tablas vienen dadas la porosidad total y la distribución del tamaño de los poros en cada teja, ya sea heladiza o no.

De estas tablas se deduce que los materiales poco resistentes al hielo tienen un porcentaje relativamente reducido de poros superiores a $1 \mu(24,2,22,8,11,1$ y $21,1 \%)$ y un porcentaje elevado de microporos inferiores a $0,1 \mu(32,2,50,4,42,0$ y $44,7 \%)$.

Completamente diferente es la cuestión respecto a las tejas resistentes al hielo, y en el artículo se facilitan datos sobre la porosidad de diez productos. En éstos el porcentaje de poros de gran diámetro (por encima de $1 \mu$ ) va del 61,0 al 85,5 \% (con una excepción del $39,1 \%$ ), mientras que el porcentaje de microporos (inferior a $0,1 \mu$ ) varía del 0,3 al $3,2 \%$. También se indica la influencia de la temperatura de cocción sobre la porosidad.

Un ladrillo que, cocido a $900^{\circ} \mathrm{C}$, presentaba un porcentaje de tan sólo un $14 \%$ de poros gruesos (así como un elevado contenido de poros finos, al nivel del $43 \%$ ) y que no era resistente al hielo, cocido a $1.000^{\circ} \mathrm{C}$ ha presentado un porcentaje del $35,5 \%$ de poros gruesos y del 8,9 \% de microporos, llegando a ser resistente al hielo. Elevando la temperatura de cocción a $1.100^{\circ} \mathrm{C}$ los poros gruesos se elevan al $47,9 \%$, y a $1.200^{\circ} \mathrm{C}$, hasta el $66,4 \%$. Los poros finos, por el contrario, bajan al 7,1 y 10,6 \%, respectivamente.

En otro caso, una teja no resistente al hielo, cocida a $900^{\circ} \mathrm{C}$, presentaba un contenido de poros gruesos de $20,2 \%$ y de poros finos del $16,6 \%$; cocida a $1.000^{\circ} \mathrm{C}$ la teja resultó resistente al hielo, con un porcentaje de poros gruesos y finos del 66,5 y del $2 \%$, respectivamente. A $1.100^{\circ} \mathrm{C}$, tales porcentajes llegaron a ser del 81,8 y del $3,5 \%$, respectivamente. Los valores de la porosidad total, que también son indicados en la tabla, revelan que aquella no es de hecho indicativa de la resistencia al hielo, en lo que tiene importancia sólo la distribución de los diferentes tamaños. Sobre éstas ejerce una notable influencia la composición mineralógica de la materia prima.

Varias probetas, constituidas esencialmente por caolinita, illita o montmorillonita, fueron cocidas a temperaturas entre $600^{\circ}$ y $1.150^{\circ} \mathrm{C}$, manteniéndose la temperatura máxima durante un tiempo de 3 horas; sucesivamente se midieron los tamaños de los poros en un entorno entre 10 y $0,01 \mu$. El gráfico de los resultados presenta notables variaciones.

En el caso de la caolinita las probetas cocidas han mostrado muchos poros finos, y, a temperaturas cada vez mayores, sólo se han comprobado pequeñas variaciones. Un notable cambio se ha producido algunas veces cuando la temperatura ha superado los $1.100^{\circ} \mathrm{C}$, hasta los $1.150^{\circ} \mathrm{C}$, lo cual es atribuido por el autor del estudio a la formación de mullita secundaria y a que se han llegado a formar gruesos cristales de este mineral.

De una manera totalmente diferente se comporta la mullita: a $700^{\circ} \mathrm{C}$ los poros entre 1,66 y $0,01 \mu$ aparecen uniformemente repartidos, y a $900^{\circ} \mathrm{C}$ se produce un considerable aumento de la porosidad con diámetros entre 1,66 y $10 \mu$. A $1.000^{\circ} \mathrm{C}$ los poros inferiores a 
$0,4 \mu$ desaparecen prácticamente. Estas variaciones de la porosidad preceden paralelamente a la desaparición de la estructura illítica y a la formación de mullita, cuarzo y espinela. A $1.100^{\circ} \mathrm{C}$ tiene lugar la sinterización y sólo quedan macroporos.

El comportamiento de la montmorillonita es similar al de la illita. Mientras que a $800^{\circ} \mathrm{C}$ más del $10 \%$ del volumen total de los poros están constituidos por diámetros inferiores a $0,2 \mu$, con el aumento de la temperatura tal porcentaje decrece, y a $1.050^{\circ} \mathrm{C}$ es sólo del $2 \%$. Como en el caso de la illita, aumenta el porcentaje de poros gruesos (entre 1,66 y $10 \mu)$. La montmorillonita desaparece formándose cristales de espinela y cristobalita.

Las arcillas holandesas están constituidas en gran parte por illita y cuarzo en proporciones variables. Durante la cocción los constituyentes de la arcilla se vuelven más o menos fluidos, lo que comporta un alargamiento de los poros. Por otra parte, según Zagar, la sección de los poros se hace menos angulosa y las paredes resultan más redondeadas y más lisas, en tanto que aumenta el número de poros gruesos a costa de los finos.

Sobre los fenómenos citados tiene gran influencia, tanto la temperatura como la duración de la cocción. Una teja incompletamente cocida y cuyo interior no ha alcanzado la temperatura necesaria presenta estratos de diversa estructura, y cuando se la somete a la prueba de heladicidad aparece con una clara fisuración. Para aumentar el tamaño de los poros existen las siguientes posibilidades:

- adición de constituyentes de granulometría gruesa, tales como arena, arcilla magra, tierra cocida finamente molida;

- adición de materiales sólidos combustibles, como serrín, cenizas volantes o polvo de carbón ;

- adición de pequeñas esferitas de poliestireno (el Styropor de la Basf), las cuales se mezclan íntimamente y proporcionan una superficie lisa (según Amrein y Gloor);

— añadiendo arcillas dilatadas (según Piltz).

Los resultados dependen generalmente en gran medida de la naturaleza de la materia prima.

Puesto que la resistencia al hielo no es de por sí misma una magnitud absoluta (como lo es, por ejemplo, la resistencia a la compresión), ya que aquélla depende del clima, no se puede establecer una regla de carácter general a la cual deban satisfacer indistintamente todas las tejas. En lo que se refiere a lo demás, los métodos de medida de la heladicidad presentan diferencias de un país a otro. A título de ejemplo se recuerda el método que se sigue en el "Centre Technique des Tuiles et Briques" de París (que es el laboratorio de la industria francesa de los ladrillos), según el cual los ciclos se efectúan a la cadencia de 6 cada 24 horas. Las tejas se clasifican en cuatro grupos, de acuerdo con su comportamiento; es decir:

- grupo A: al cabo de 25 ciclos la teja presenta daños; estas tejas pueden ser empleadas en cualquier clase de condiciones;

- grupo B: al cabo de 18 ciclos la teja no presenta ningún daño significativo, y después de 25 ciclos no se observa ninguna fisura importante y la pérdida de peso no sobrepasa al $1 \%$; éstas pueden utilizarse en casi todas las partes, excepto en climas particularmente rigurosos; 
- grupo C: al cabo de 12 ciclos la teja no muestra ningún daño significativo, y después de 25 ciclos la pérdida de peso no es superior al $5 \%$; éstas son inadecuadas en ciclos rigurosos, mientras que en climas benignos se comportan bien en la mayoría de los casos, como, por ejemplo, en la costa mediterránea y en los alrededores de $\mathrm{Pa}$ rís ;

- grupo D: al cabo de 12 ciclos aparecen ya daños sensibles, y después de 25 ciclos la pérdida de peso es superior al $5 \%$; en éstas hay, en mayor o menor grado, peligro de daños graves.

Existe un método de pruebas de heladicidad desarrollado por Enberg en el laboratorio de Estocolmo de la industria de los ladrillos sueca, en el cual se utiliza un carrito sobre el que se monta un trozo de cubierta. Después de rociarlo con agua, que está a una temperatura de $2^{\circ}$ ó $3^{\circ} \mathrm{C}$, se introduce dicho carrito en un frigorífico donde la teja puede ser sometida al hielo únicamente por su parte superior o, si se desea, por ambas caras. Cuando el hielo actúa sobre una sola cara, se forma sobre la teja al cabo de unos pocos minutos una fina capa de hielo. Se somete ahora a la teja al deshielo de modo que éste se verifique tan sólo en una profundidad de 2 ó $3 \mathrm{~mm}$ bajo la superficie superior. Con este dispositivo se puede producir así en la teja un doble estrato de hielo, en cuyo interior existe agua.

El rociado dura 4 minutos, el período de prueba al hielo es de 30 minutos, y entre la entrada y la salida del carrito transcurren otros 2 minutos; en total, requieren un ciclo de 36 minutos. Se juzga que una teja es resistente al hielo si soporta, sin daños, 250 ciclos.

El artículo se detiene sólo brevemente en la medida indirecta de la heladicidad (coeficiente de saturación, etc.), obteniéndose la conclusión de que la prueba directa de la heladicidad, el examen microscópico y la determinación de la granulometría son los métodos que han dado los mejores resultados.

También se hace una alusión a la investigación suiza sobre el tejado de pruebas de Melchthal, como asimismo a la prueba comparativa entre los diferentes métodos realizados en Alemania, Suiza y Suecia.

En Holanda, en el año 1958, la Asociación de Productores de Tejas (Nedaco) ha constituido una comisión de "Heladicidad", que se propone tres fines:

- el primero, establecer qué métodos permiten juzgar mejor el resultado en obra de las tejas producidas en Holanda;

- el segundo, investigar la causa real de los daños, y

- el tercero, en fin, verificar qué relaciones existen entre el comportamiento de los materiales durante las pruebas y su comportamiento real.

Para tales estudios se ha preparado una colaboración con el Centro Técnico de París antes citado. Por otra parte se están realizando regularmente controles de fabricación y toma de muestras sistemáticas. 
NOTA: Sobre el tema de la heladicidad, "L'Industria Italiana dei Laterizi" ha publicado los siguientes trabajos:

\section{Artículos}

6/1951. L. A. Poggr: A propósito de la definición física de la heladicidad de los cuerpos porosos.

6/1953. L. A. Poggr: Determinación del coeficiente de saturación para la medida de la heladicidad de los ladrillos.

5/1954. E. LUTHER: Comisión "Heladicidad" del T.E.B.

2/1957. Actividad de la Comisión "Heladicidad" del T.E.B.

2/1958. L. Alviset, C. Liger: Recientes resultados en los estudios de la resistencia al hielo (resumido).

4/1958. La resistencia de las tejas al hielo -I. parte- (Comisión "Heladicidad" del T.E.B.).

6/1958. La resistencia de las tejas al hielo - II. parte- (Comisión "Heladicidad" del T.E.B.).

1/1960. J. JESSING: Consideraciones sobre la resistencia de las tejas al hielo.

2/1960. F. SANDORF: Recientes experiencias suecas.

2/1961. H. LehmanN: La prueba dilatométrica de resistencia al hielo de los productos cerámicos (resumido).

3-4/1961. H. HARkoRT: La resistencia al hielo en relación con el tamaño, distribución y forma de los poros.

4-5/1967. G. PILtz: Influencia de los procedimientos de producción sobre la heladicidad de las tejas.

6/1968. W. NeumanN: La teja no heladiza.

1/1971. M. Albenque, C. Dampoux y L. Collon: Métodos de control de resistencia al hielo. Rúbrica "Rassegna della Stampa Tecnica".

4/1955. J. Labansat: La acción del hielo sobre los ladrillos.

1/1956. K. BERGMANN : Investigación sobre la influencia de la composición, temperatura de cocción y forma de los productos sobre la resistencia al hielo.

4/1964. B. Butterworth: Resistencia al hielo de los ladrillos y tejas.

5/1964. Estudio de la porosidad en el laboratorio.

6/1969. C. O. Pels Leusden: Moldeo de las tejas y daños producidos por el hielo.

6/1970. J. Burka y J. Novotny: Nuevos procedimientos para la medida de la heladicidad de los materiales. Rúbrica "Noticias varias".

4/1971. Estudio comparativo sobre los métodos de laboratorio para la determinación de la resistencia al hielo. 